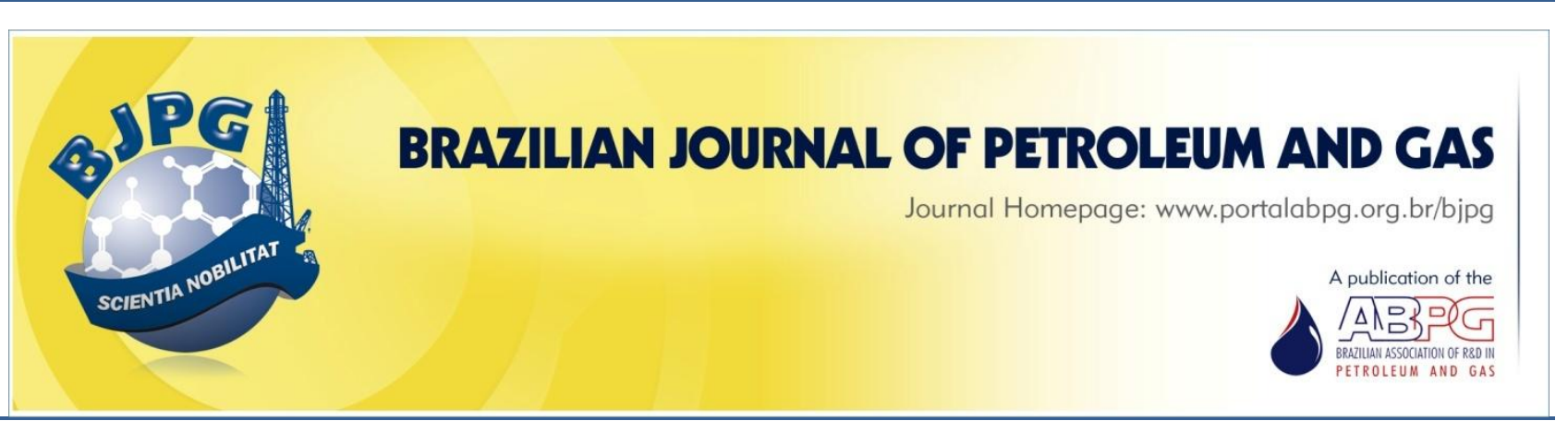

\title{
PECTIN AS NATURAL GAS HYDRATE INHIBITOR: APPLICATION OF THE AVRAMI MODEL
}

\author{
a,c Silva, B. L. L. D.; ${ }^{b}$ Silva, B. C. L. D.; ${ }^{a}$ Fialho, B. O.; ${ }^{c}$ Ferraz, I. L.; ${ }^{\text {a,c }}$ Vitorazi, L.; ${ }^{\text {Castro, J. A. }}{ }^{1}$ \\ ${ }^{a}$ Fluminense Federal University (UFF), Graduate Program in Metallurgical Engineering (PPGEM), Volta Redonda - RJ - Brazil \\ ${ }^{b}$ Fluminense Federal University (UFF), Graduate Program in Mechanical Engineering (PGMEC), Volta Redonda - RJ - Brazil \\ ${ }^{\mathrm{C}}$ Fluminense Federal University (UFF), Polymer Material Laboratory, Volta Redonda - RJ - Brazil
}

Received: 08.01.2019 / Revised: 08.05.2019 / Accepted: 08.05.2019 / Published on line: 18.06.2019

\begin{abstract}
The study of gas hydrate formation has attracted researchers' attention due to the importance of this topic to oil and gas industries. Gas hydrates can interrupt flow during the petroleum extraction resulting in production losses as well as in safety concerns. Understanding the kinetics of the process is useful to delay hydrate formation by using kinetic inhibitors that are applied often at lower concentrations. Acquisition of experimental data on the process is important to predict ranges of conditions for hydrate formation. This work applies the Johnson-Mehl-Avrami-Kolmogorov (JMAK) phenomenological model for a set of data acquired for pectin, a natural polymer used as kinetic inhibitor, to predict the fraction of hydrate formed. Results suggest the use pectin as potential natural hydrate inhibitor, considering that the data are in agreement with the model's prediction.
\end{abstract}

\section{KEYWORDS}

gas hydrate; kinetic inhibitors; pectin; natural inhibitors; JMAK model

\footnotetext{
${ }^{1}$ To whom all correspondence should be addressed.

Address: Fluminense Federal University (UFF), EEIMVR, Ave. dos Trabalhadores, N. 420, Volta Redonda, RJ, Brazil. ZIP Code: 27225-125 | Phone number: +55 (24) 981128078 | e-mail: joseadilsoncastro@id.uff.br doi:10.5419/bjpg2019-0008
} 


\section{INTRODUCTION}

Gas hydrates are ice-like structures composed of small gas molecules (such as methane, ethane, and propane) and water, formed at low temperatures and high pressure (Xu et al., 2010). Hydrate crystallization process can be divided into two main stages: nucleation and growth. Nucleation stage, in turn, can be induced through crystal seeds or can occur spontaneously through random molecular interactions. The first hydrate nuclei (clusters) are formed in the nucleation stage, and a critical radius must be reached before additional growth becomes thermodynamically favorable (Kaschiev, 2000). The conditions of formation and stability of gas hydrates are determined by the relationship between three variables: concentration of the hydrate-forming gas, temperature, and pressure (Oliveira et al., 2010).

There are three main families of hydrates, which have a crystal structure determined mainly by the largest guest molecules in the structure. Guest sizes (largest van der Waals diameter) cover a range from 0.4 to $0.9 \mathrm{~nm}$ and include almost all chemical functionalities (Ripmeester \& Alavi, 2016). The three main families of gas hydrates are the cubic structures $\mathrm{I}$ and $\mathrm{II}$ and the $\mathrm{H}$ hexagonal structure (Trueba et al., 2014), as displayed in Figure 1.

Over recent years, natural gas hydrates have been the focus of many studies due to their wide applicability as a new source on natural gas and as a means for novel applications like carbon dioxide capture, hydrogen storage, and natural gas storage and transportation. Natural gas hydrates, mainly methane, contain highly concentrated methane gas (Siangsai et al., 2015).

Natural gas hydrate reservoirs contain high concentrations of methane gas. A study by the United States Geological Survey (USGS) estimates that the amount of natural gas stored as hydrate in permafrost and ocean sediments is twice that of all other fossil fuels combined (Gandara et al., 2015).

Despite all the advantages of gas hydrates present to be used as energy source for the future and their abundance throughout the world, our insufficient understanding of hydrates has limited their extraction. If in one hand gas hydrates have a great potential as an energy source, on the other hand they can create hydrate blockages capable of obstructing oil/gas pipelines, compromising transportation and posing threats to oil and gas industries (Sa et al., 2016). According Daraboina et al. (2014), the formation of gas hydrates is one of the major challenges of the oil and gas industry in the last decades.

Companies in the oil sector are continually working to increase the exploration and production of oil and gas. In some systems, the fluids from the reservoir (gas, oil, and water) are directed to the platform through a pipeline, where processing is performed. These pipes remain under extreme conditions of low temperatures and high pressures, providing favorable conditions for the formation of

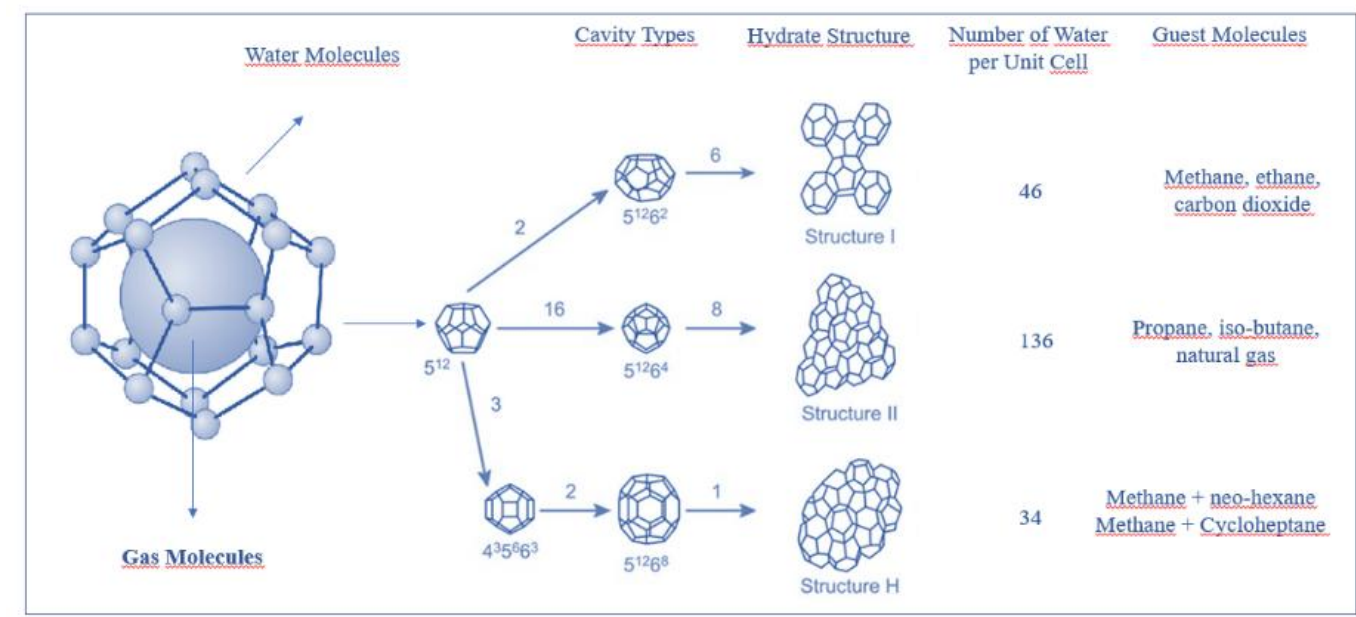

Figure 1. Unit cells of some gas hydrate structures: structure I, structure II, and structure H (adapted from Nago \& Nieto, 2011). 


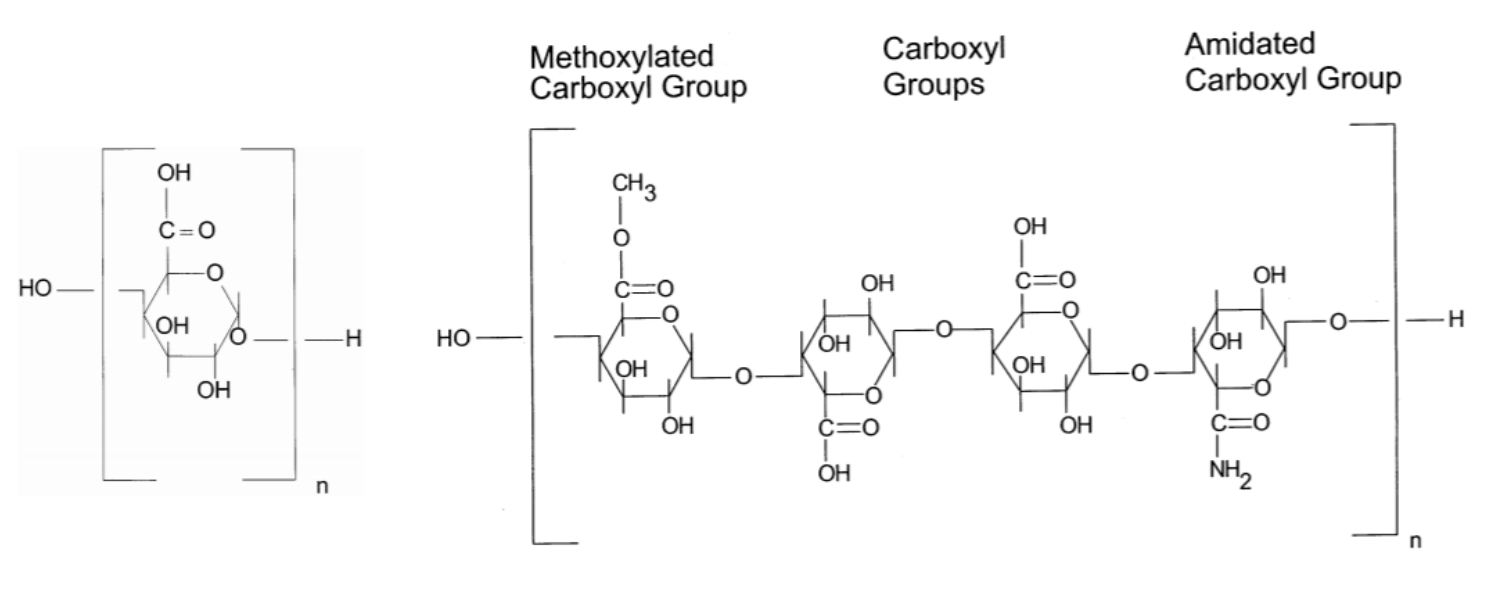

(a)

(b)

Figure 2. Chemical structure of polygalacturonic acid (a) and representative chemical structure of pectin showing typical repeating groups (b) (White et al., 1999).

gas hydrates. Thus, understanding the kinetics of hydrate formation and its dissociation is very important for the oil industry as it needs to maintain unrestricted flow of oil and gas into pipelines (Tang et al., 2017).

Traditionally, hydrate formation has been avoided by using thermodynamic inhibitors, such as methanol or glycol, at high dosages (Daraboina et al., 2011). In Brazil, the usage of ethanol is common. However, economic and environmental factors, besides technical problems associated with thermodynamic inhibitors, have motivated the research and development of alternative technologies to avoid hydrate formation, to include using a low dosage hydrate inhibitors (LDHIs) (Daraboina et al., 2013). According Daraboina et al. (2011), LDHIs can be classified by their behavior; some LDHIs prolong the induction time for hydrate nucleation (kinetic hydrate inhibitor, KHIs), while others prevent the agglomeration of hydrate crystal (anti-agglomerants).

In recent years, natural inhibitors as chitosan, tapioca, amino acid, and antifreeze protein have been object of research (Xu et al., 2010; Lee \& Englezos, 2007; Daraboina et al., 2011; Sa et al., 2013; Walker et al., 2015; Sa et al., 2016; Perfeldt et al., 2014; Xu et al., 2016ab). These natural products showed positive effects on hydrate inhibition.

The polysaccharide pectin is also among the environmentally friendly alternative kinetic inhibitors. Pectin belongs to the family of complex heteropolysaccharides and consists predominantly of partially methoxylated galacturonic acid residue. It is widely present in almost all fruits and vegetables as the structural unit of fresh cells and the junction between the cells. Its structure is based on 1,4-linked $\alpha$-D-galacturonic acid, interrupted by L-rhamnose residues with sidechains of neutral sugars, mainly D-galactose and Larabinose (Guo et al., 2014). Figure 2 shows the general structure of pectin with chemical structure of polygalacturonic acid (a) and typical repeating units that could be metoxylated carboxyl, carboxyl, and amidated carboxyl groups.

Pectin, as a well-known food additive, is widely used as thickener, texturizer, emulsifier, and stabilizer agent in a variety of industrialized food, pharmaceutical, and cosmetic products. Studies also suggest that pectin can be used in the pharmaceutical industry for its ability to reduce cholesterol levels inhuman blood (Silva et al., 2016). Pectin can be extracted from various agricultural by-products, including orange peel, apple pomace, lemon, and sugar beet pulp (Guo et al., 2014). According to Guo et al. (2014), the orange peel and apple pomace stand out because they are abundant and contain high levels of pectin polysaccharides.

Studies of pectin as a natural inhibitor have been developed recently by Xu et al. (2016a) and Xu et al. (2016b) in their articles entitled "Pectin as an Extraordinary Natural Kinetic Hydrate Inhibitor" and "Molecular Dynamics Simulation of Methane Hydrate Growth in the Presence of the Natural 
Product Pectin," respectively. According to Xu et al. (2016a), pectin has good inhibition performance allied to high biodegradability and competitive cost.

In their paper, Xu et al. (2016a) analyzed the polysaccharide pectin as a natural inhibitor at concentrations of 0.25 and 0.5 wt.\% for subcoolings of 10 and $12.5^{\circ} \mathrm{C}$ and pressures of 95 and 115 bar. The performance of pectin was compared to the performance of the synthetic inhibitor PVCAP. The authors analyzed gas consumption and pressure over time. Later, Xu et al. (2016b) performed a molecular dynamics simulation of the gas hydrate growth in the presence of pectin. Pectin was evaluated at concentrations of 2.46 and $3.62 \mathrm{wt} . \%$, at $260 \mathrm{~K}$ and 150 bar. The authors also evaluated the variation of total energy over time for the different systems.

Continuing the study of pectin as a natural gas hydrate inhibitor, this paper analyzes the concentrations of $0.3,0.5$, and $1.0 \mathrm{wt} \%$ for the subcoolings of 7,9 , and $11^{\circ} \mathrm{C}$ at a pressure of 100 bar (APPENDIX A). The study allowed the evaluation of gas consumption, pressure variation over time, and rate of hydrate formation under certain conditions using the Johnson-Mehl-AvramiKolmogorov (JMAK) phenomenological model to predict the fraction of hydrate formed.

Assuming that hydrate formation is a process analogous to that of crystallization, characterized by nucleation and growth mechanism, the fraction of the hydrate formed obtained experimentally can be compared with the fraction of the hydrate formed calculated by classical theory of JMAK.

JMAK's model describes the kinetics of phase transformation based on the assumption of spatially random nucleation, considering the growth rate as constant (Rios \& Padilha, 2007). The kinetics of isothermal phase transformations have been described by the JMAK phenomenological model since the 40's, and, although many theoretical investigators have contributed with new improvements to extend the range of applicability of this model, the experimentalists keep using it in its original form due to its simplicity (Fanfoni \& Tomellini, 1998). The essence of the model initially proposed for isothermal transformation in solids can be summarized in the relation presented in Eq. 1: $f(t)=1-\exp ^{\left(-\left(k \cdot t^{n}\right)\right)}$

Where, $t$ is the effective time, $n$ is the exponent of Avrami, and $k$ is a dependence of the kinetic rate constant. According to Rios and Padilha (2007), the JMAK model follows a sigmoidal fit and the values of $k$ and $n$ are found by fitting the experimental data.

The JMAK equation follows a sigmoidal fit and is used most commonly in its linearized form (Rios \& Padilha, 2007) described by Eq. 2.

$\ln \ln (1 /(1-f(t)))=\ln (k)+n \ln (t)$

This kinetic rate constant is dependent of the temperature and it is assumed to be an Arrheniustype relation, given by the Eq. 3. Usually, Eq. 3, is applied in its linearized form as indicated in Eq. 4.

$k=k_{0} \cdot \exp ^{\left(-E_{a} / R T\right)}$

$\ln (k)=\ln \left(k_{0}\right)-E_{a} / R T$

Where, $k_{0}$ is the frequency factor, $E_{a}$ is the activation energy, $R$ is the universal gas constant, and $T$ is the temperature.

The error in the JMAK model was predicted using the mean absolute percentage error (MAPE). According Khair et al. (2017), MAPE is a metric commonly used to calculate the margin error from predicted least square method of data. Eq. 5 represents the formula for measuring the MAPE (\%) (Kumar et al., 2016).

$M A P E=\frac{\left(\sum_{i=1}^{n}\left(E_{i}-F_{i}\right) / E_{i}\right) \times 100}{n}$

Where, $E_{i}$ is the experimental data, $F_{i}$ is the Avrami fit data for hydrate conversion ratio, and $n$ is the number of observations.

Therefore, the present work aims to support the understanding of the mechanisms of gas hydrate formation and inhibition as well as to reinforce the performance of polysaccharide pectin as a natural kinetic inhibitor on the nucleation of gas hydrates. 


\section{EXPERIMENTAL PROCEDURE}

Pectin (Dinâmica, Brazil), with high degree of methylation (DM > 50\%) and a viscosimetric molecular weight of $500 \mathrm{kDa}$ was used without previous purification. Further information on pectin is available on sections S1 and S2 at SI). Pectin solutions were prepared by stirring overnight the powder material under concentrations of 0.3 to $1 \mathrm{wt} . \%$ in distilled water, where the concentrations studied were set according to Xu's work (Xu et al., 2016a). Methane gas (code N45) was acquired from Air Liquide.

Experiments involving the kinetics of gas hydrate formation were performed at the Fluids and Thermo Sciences Laboratory of the Engineering School of Fluminense Federal University using a high pressure cell from Hydrafact Ltd. (United Kingdom) with the refrigerated/heating circulator F25 from JULABO (Germany), coupled. The device consists of a jacketed cylinder $\left(\sim 290 \mathrm{~cm}^{3}\right)$ where the solution is placed. The system is kept at constant temperature by water circulating from a thermostatic bath and it is under homogeneous mechanical agitation. The gas was supplied by a high-pressure vessel, which was connected to the cell where there is a pressure control (see section S3 at SI).

The experiments were conducted using methane as hydrate-forming gas at a stirring rate of 500 RPM, over a range of temperatures $\left(2^{\circ} \mathrm{C}^{\sim} 6^{\circ} \mathrm{C}\right)$ for subcooling of 11,9 , and $7^{\circ} \mathrm{C}$, and at a pressure of 100 bar. Aditionally, experiments were performed by isochoric method: after temperature stabilization of the solution, the cell was closed and pressurized at 100 bar. At these conditions, one can expect to observe the formation of gas hydrates with structure of type I, as previously discussed. Additionally, Figure 3 presents a predicted/simplified phase diagram $P-T$ that provides a continuous line for hydrate formation and dissociation equilibrium. The hydrate formation envelope presented in Figure 3 was simulated using thermodynamic software PVTSIM from Calsep a.s. (Denmark). Above the continuous line, hydrate plus excess phases coexist, and below the continuous line there are free water and free gas. The dots at Figure 3 show the conditions where the experiments were conducted, at a region where hydrates are thermodynamically stable and have the potential to form (Bai \& Bai, 2005).

The formation of the hydrate was monitored through integrated commercial software, which recorded all temperature, pressure and torque variations that occurred while the experiment was in progress. Data were collected every 10 seconds over a time period of 6 hours, and the experiments were made in triplicates. Hydrate formation was identified by a pressure decrease and a temperature increase. Since there is methane consumpion for hydrate formation, it results is an exothermic process (Siangsai et al., 2015).

Pressure and temperature data were used to

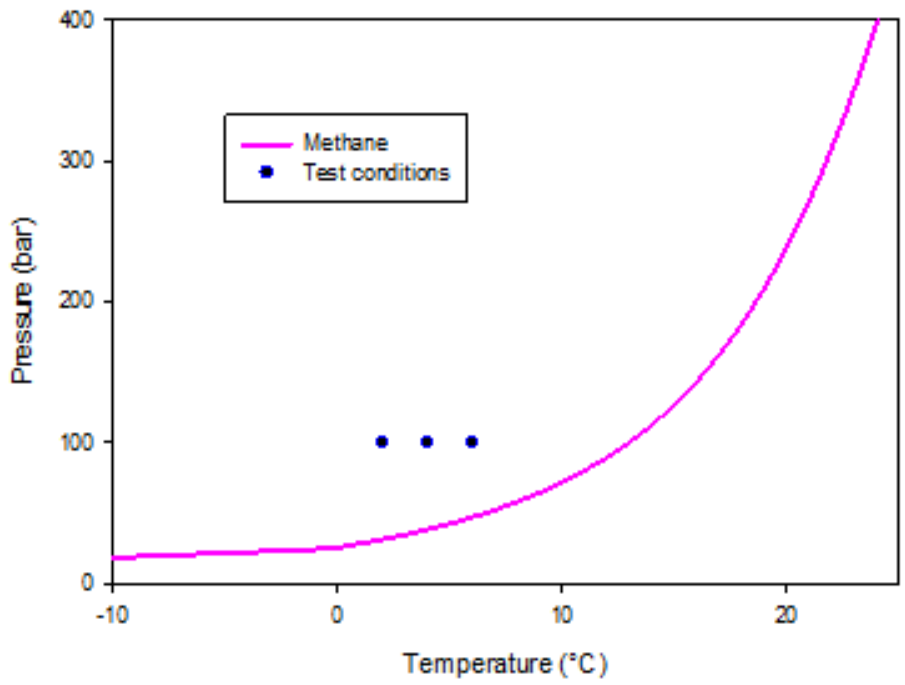

Figure 3. Graph displays a typical phase diagram for a mixture of methane and water. Dots represent the conditions used at the experimental study. 


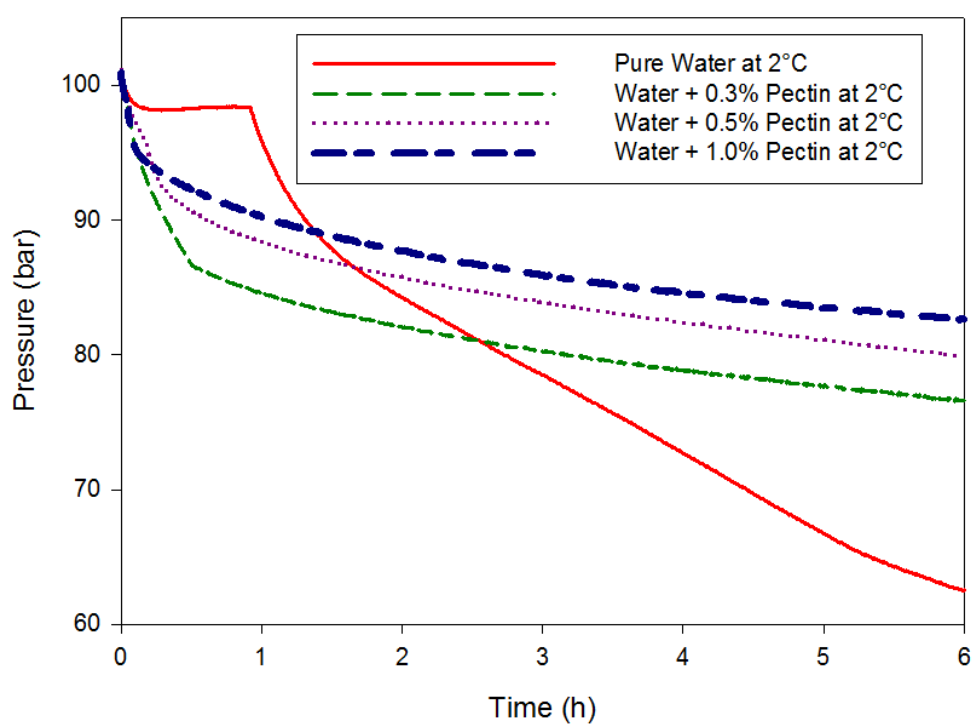

Figure 4. Pressure versus time plot for pure water and aqueous solutions of pectin at different concentrations and temperature of $2^{\circ} \mathrm{C}$.

calculate methane consumption (moles of methane consumed). Moles of the consumed gas for hydrate formation at time $t$ is given by Eq. 6 from Siangsai et al. (2015). The gas compressibility factor (Z) was determined according to the Lee Kesler generalized correlation table.

$\Delta n_{H}=n_{H, 0}-n_{H, t}=$

$=(P V / Z R T)_{G, 0}-(P V / Z R T)_{G, t}$

Where $\Delta n_{H}$ is the number of moles of gas consumed for hydrate formation in the monitored interval of the experiment (mol). $P$ is the pressure $(\mathrm{Pa}), \quad V$ is the gas volume $\left(\mathrm{m}^{3}\right), Z$ is the compressibility factor, $R$ is the universal gas constant $\left(8.31 \mathrm{~m}^{3} \cdot \mathrm{Pa} \cdot \mathrm{K}^{-1} \cdot \mathrm{mol}^{-1}\right), t$ is time, and $T$ is the temperature $(K)$ in the reactor cell. Subscripts $G, O$ and $G, t$ represent the gas phase at time zero and time $t$, respectively.

The discrete forward difference method (Eq. 7) was used to calculate the rate of methane hydrate formation (Tian et al., 2017).

$\frac{d n_{t}}{d t} \cong\left(\Delta n_{H, t+\Delta t}-\Delta n_{H, t}\right) / \Delta t$

Where $\Delta t$ is the time difference between two observations.

\section{RESULTS E DISCUSSIONS}

The addition of many solutes into water can modify the equilibrium conditions of the system and/or the kinetics of a hydrate formation process (Ribeiro \& Lage, 2008). Experimental and theorotical studies indicate the action of pectin as a natural gas hydrate inhibitor. At the present work, the main issue is to evaluate the kinetics of the process of gas hydrate formation applying the JMAK's model to predict parameters as a function of temperature.

Figures 4-6 show the behavior of pressure as a function of time for samples containing water and methane with 0-1 wt.\% of pectin, at different temperatures. In all graphs, it is possible to see a pressure drop with time, and it can be explained by the incorporation of gas molecules in water. This consumption of gas occurs with the gas hydrate formation. For curves with pure water for temperatures of 2 and $4^{\circ} \mathrm{C}$ (Figs. 4 and 5), these two events occur up until $2 \mathrm{~h}$, and, then, a sharp decrease in pressure is associated to an increase in rate of conversion of hydrates. Sometimes both events happen at the same time, as one could observe in the experiments made with pectin solutions.

For curves with pectin, more than just pressure drop, Figure 4 shows a positive influence of pectin in the retardation of hydrate formation curve at $2{ }^{\circ} \mathrm{C}$. In this sense, best results were obtained for pectin concentration of $1 \mathrm{wt} . \%$. Some inhibition was observed at low concentrations of pectin (0.3-0.5 wt.\%). As expected, a similar thermodynamic behavior was found for experiments conducted at 4 and $6^{\circ} \mathrm{C}$ (Figure 5). 


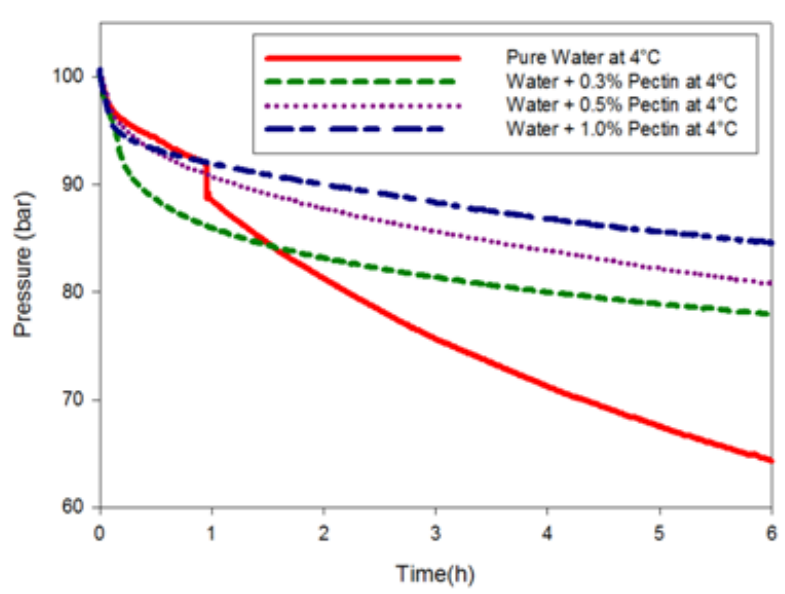

(a)

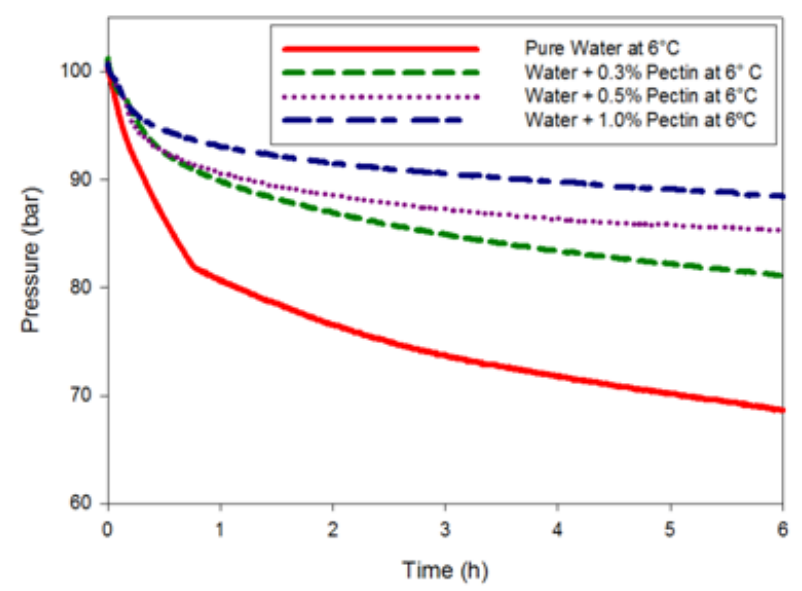

(b)

Figure 5. Pressure versus time plot for pure water and aqueous solutions of pectin at different concentrations and temperatures of $4^{\circ} \mathrm{C}(\mathrm{a})$ and $6^{\circ} \mathrm{C}(\mathrm{b})$.

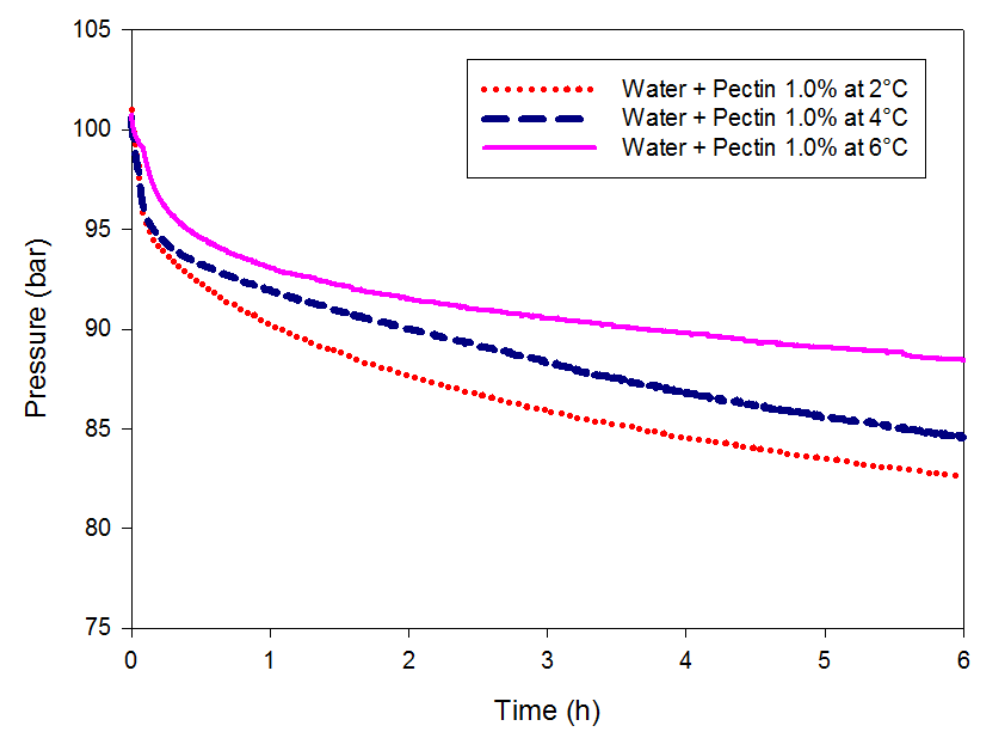

Figure 6. Pressure versus time plot for the system pectin aqueous solutions with $1.0 \mathrm{wt} . \%$ at different temperatures.

According to the results presented above, it is possible to reinforce the idea that water plus pectin delayed the rate of gas hydrate formation. For higher pectin concentrations, lower are the pressure drop rate and the hydrate conversion. Nevertheless, pectin showed little or no effects on delaying hydrate nucleation, as it is not possible to separate gas dissolution and nucleation events in most of pressure curves.

According Ribeiro and Lage (2008), hydrate formation is a phase change process which requires a supersaturated environment to take place. Due to this supersaturation, the Gibbs free energy of the gas dissolved in the liquid is higher than the Gibbs free energy of the hydrate, and it favors the aggregation of water and gas molecules to form the hydrate.

Figure 6 demonstrates that increasing subcooling by lowering the temperature, the rate of hydrate formation increases. This behavior was confirmed by Bai and Bai (2012) who affirmed that when subcooling increases, hydrate formation time decreases exponentially. The best results, in this work, were obtained for pectin concentration of 1 wt. $\%$ at $6^{\circ} \mathrm{C}$. 


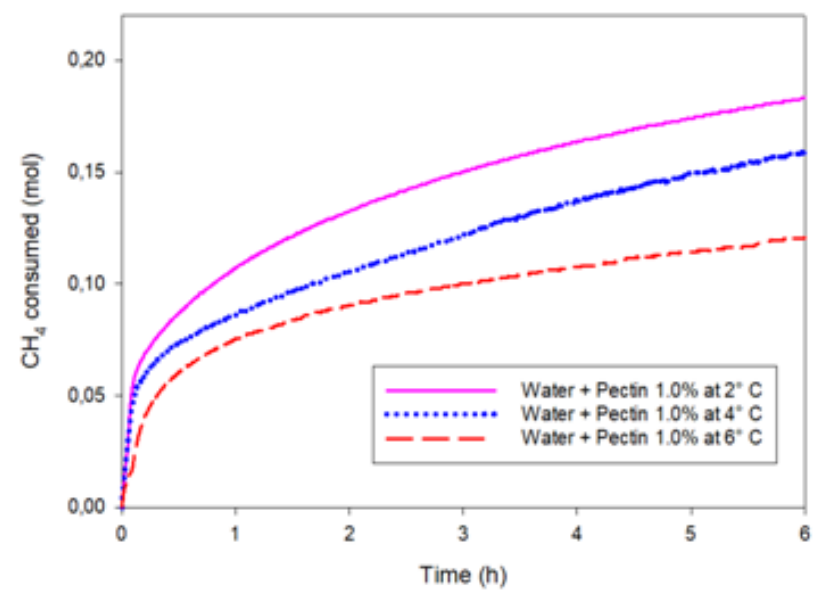

(a)

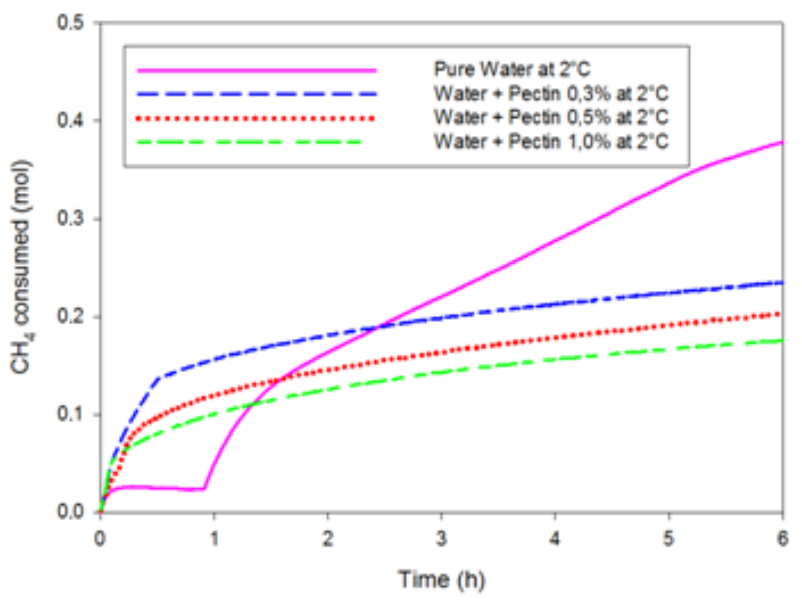

(b)

Figure 7. Gas uptake curves during methane hydrate formation in aqueous pectin solutions for pressure of 100 bar with 1.0 wt.\% at different temperatures (a) and at $2^{\circ} \mathrm{C}$ at different pectin concentrations.

The gas uptake for samples containing pectin with $1 \mathrm{wt} . \%$ at different temperatures and at $2^{\circ} \mathrm{C}$ for different pectin concentration is shown at Figures 7-a and 7-b, respectivelly. The amount of gas consumed during methane hydrate formation also demonstrates that the lower subcooling and the higher the pectin concentration are there is a decrease in gas hydrate formation, according to Figure 7-a.

Siangsai et al. (2015) also determined curves of gas uptake versus time for their investigation of the roles of activated carbon particle sizes on methane hydrate formation, finding a similar behavior. According the authors, after introducing methane as gas into the system, there is a gas diffusion into water before hydrate formation, and this behavior can be observed at the beginning of the methane consumption curve. After that, the hydrate starts to form by rapidly consuming methane gas.
Methane gas consumption remains during hydrate crystal growth, until it reaches the equilibrium. Hydrate formation rate is controlled by the pressure, temperature, and composition of the system. The surface tension of the liquid also has an important influence on the hidrate formation (Tian et al., 2017).

The classical Johnson-Mehl-AvramiKolmogorov approach for nucleation and growth models was revisited and applied in this work to find the fraction of gas hydrate formed under these condictions. Parameters $k$ and $n$ of the equation of JMAK (from Eq. 3), for the systems composed of water and 0.3 and $1 \mathrm{wt} . \%$ of pectin at different temperatures, were obtained with a regression analysis and are represented in Table 1 . The three stages of hydrate crystal growth, limited by the dominant type of resistance, were analyzed (see section $\mathrm{S} 4$ at $\mathrm{SI})$.

Table 1. Quantitative parameters adjusted to describe the kinetics of hydrate formation. Significance level of $5 \%$ ( $p<0.05)$ was adopted as the criteria for the analysis of model parameters.

\begin{tabular}{|c|c|c|c|c|c|c|c|c|c|c|c|c|}
\hline \multirow{3}{*}{ Stage } & \multicolumn{6}{|c|}{0.3 wt.\% } & \multicolumn{6}{|c|}{1.0 wt.\% } \\
\hline & \multicolumn{2}{|c|}{$2^{\circ} \mathrm{C}$} & \multicolumn{2}{|c|}{$4^{\circ} \mathrm{C}$} & \multicolumn{2}{|c|}{$6^{\circ} \mathrm{C}$} & \multicolumn{2}{|c|}{$2^{\circ} \mathrm{C}$} & \multicolumn{2}{|c|}{$4^{\circ} \mathrm{C}$} & \multicolumn{2}{|c|}{$6^{\circ} \mathrm{C}$} \\
\hline & $n$ & $\mathrm{~K}$ & $\mathrm{n}$ & $\mathbf{k}$ & $n$ & k & $\mathbf{N}$ & $\mathbf{k}$ & $n$ & $\mathbf{k}$ & $n$ & \\
\hline 1 & 0.9265 & 0.4345 & 0.7283 & 0.225 & 0.6304 & 0.1219 & 0.8509 & 0.366 & 0.7305 & 0.2483 & 0.4823 & 0 \\
\hline 2 & 0.6302 & 0.2263 & 1.2301 & 0.6133 & 0.9317 & 0.1917 & 0.3370 & 0.1142 & 0,2506 & 0,0866 & 1.2924 & 0 \\
\hline 3 & 0.2652 & 0.1674 & 0.2863 & 0.1501 & 0.3491 & 0.1167 & 0.3299 & 0.1070 & 0,3997 & 0,0827 & 0.2873 & 0 \\
\hline $1-3$ & 0.3227 & 0.1498 & 0.3318 & 0.1376 & 0.3981 & 0.1050 & 0.3460 & 0.1038 & 0.3736 & 0.0873 & 0.3302 & 0 \\
\hline
\end{tabular}

" $n$ is the exponent of Avrami and $k$ is a dependent of the kinetic constant. 


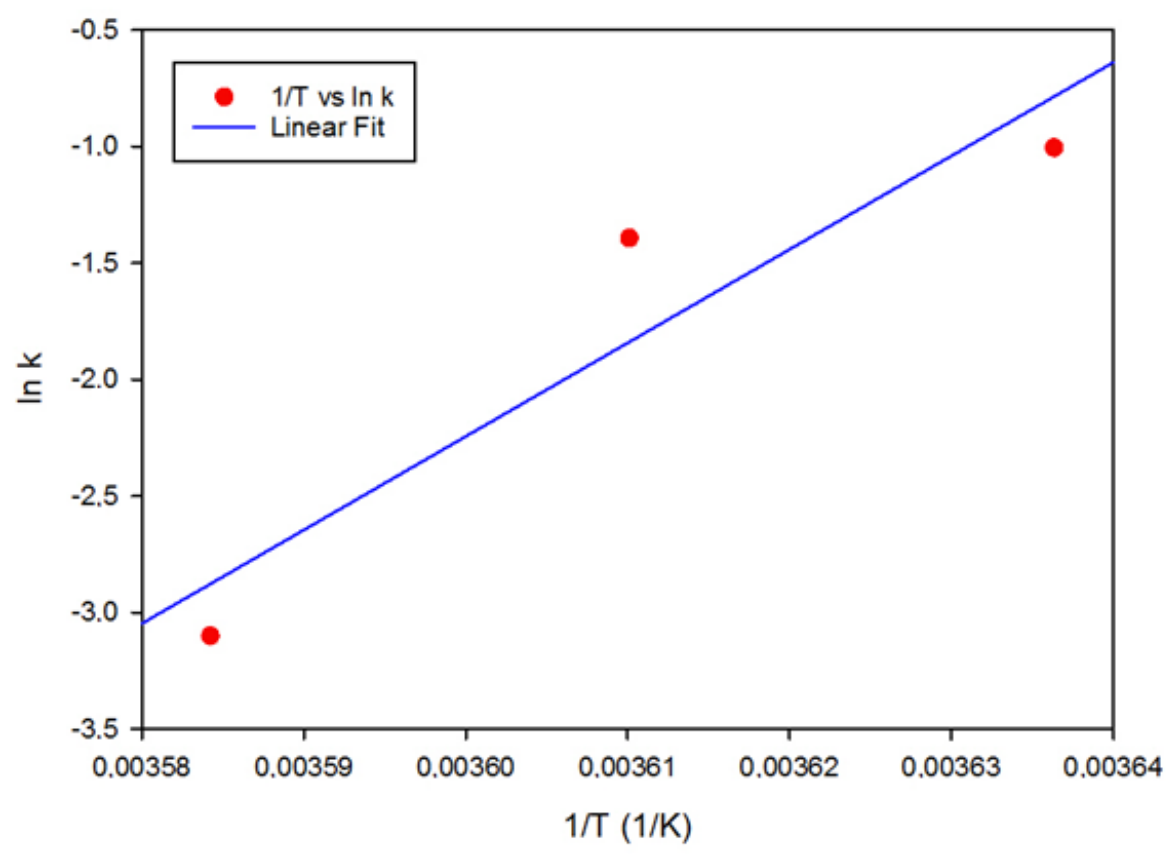

Figure 8. JMAK parameter $k$ as function of the inverse of temperature for $1 \mathrm{wt} . \%$.

From Table 1, it is possible to infer that $n$ exponent values are in the range of 0 to 1.3. According Kumar et al. (2016), $n$ value is considered to be composed of two terms $\left(n=n_{d}+n_{n}\right)$, the first represents the dimensionality of the growing crystals $\left(n_{d}\right)$ and the other represents the time dependence of the nucleation $\left(n_{n}\right)$. In the case of gas hydrates, the value of $n_{d}$ is expected to vary between half and one, depending on the degree of mass transfer resistance for gas diffusion. The $n_{n}$ value should be either 0 or 1 , where 0 corresponds to instantaneous nucleation and 1 to sporadic nucleation. Nonetheless, $\mathrm{n}$ can assume a noninteger value, as seen in this work, since in many cases the nucleation may be in between completely instantaneous or completely sporadic.

To analyze the kinetics of gas hydrate formation, gas uptake curves were fitted to the crystallization model for initial stage of hydrate formation. In addition, it was observed that the value of $k$ decreased with an increase in temperature, indicating a negative activation energy of formation reaction (Figure 8).

Amtawong et al. (2017) pointed out two possible origins for the negative activation energy. For them the negative activation energy is due the existence of metastable structures that are more favorable at low temperatures or related to the initial surface adsorption of gas onto the ice surface.

Parameters $k_{0}$ and $E_{a}$, determined through Eq. 4, are represented in Table 2. The higher the activation energy is, the slower the chemical reaction will be.

The hydrate conversion rates in the first stage of hydrate growth were well correlated by the Avrami coefficients ( $n$ and $k$ ) for this stage. However, to predict the amount of hydrate formed over time, it is suggested to use Avrami coefficients for the total time data (stage 1-3). The great fit is confirmed by the error margin calculated by Eq. 5 (Table 3).

The experimental data for the fraction of hydrate formed and the data obtained by the JMAK

Table 2. Parameters $\boldsymbol{k}_{\mathbf{0}}$ and $\boldsymbol{E}_{\boldsymbol{c}}$ adjusted to describe the kinetics of hydrate formation.

\begin{tabular}{cccc}
\hline wt.\% & Ea (kJ/mol) & $\mathbf{k}_{\mathbf{0}}$ & $\mathbf{R}^{\mathbf{2}}$ \\
\hline $\mathbf{0 . 3}$ & -202.715 & $1.35 \mathrm{E}-39$ & 0.9997 \\
$\mathbf{1 . 0}$ & -333.842 & $1.78 \mathrm{E}-64$ & 0.8805 \\
\hline
\end{tabular}


Table 3. Mean absolute percentage error (MAPE).

\begin{tabular}{cccccc} 
& & \multicolumn{4}{c}{ MAPE (\%) } \\
\cline { 3 - 6 } & & Stage 1-3 & Stage 1 & Stage 2 & Stage 3 \\
\hline \multirow{3}{*}{$\mathbf{0 , 3 \%}$} & $\mathbf{2}^{\circ} \mathrm{C}$ & -0.66 & -243.84 & -108.83 & -2.38 \\
& $\mathbf{4}^{\circ} \mathrm{C}$ & -0.41 & -145.28 & -303.92 & -1.61 \\
& $\mathbf{6}^{\circ} \mathrm{C}$ & -0.24 & -60.45 & -211.94 & -2.52 \\
\hline \multirow{2}{*}{$\mathbf{1 \%}$} & $\mathbf{2}^{\circ} \mathrm{C}$ & -0.13 & -323.49 & -7.65 & -0.44 \\
& $\mathbf{4}^{\circ} \mathrm{C}$ & -0.08 & -264.80 & 17.42 & 0.83 \\
& $\mathbf{6}^{\circ} \mathrm{C}$ & -0.42 & 12.73 & -625.14 & -1.52 \\
\hline
\end{tabular}

model for the systems formed by water and $1 \mathrm{wt} \%$ of pectin were compared in Figure 9. It is possible to observe the good adjustment of the experimental data to the JMAK model. Falenty et al. (2011), Kumar (2016), and Amtawong et al. (2017) applied the JMAK model to characterize the hydrate fraction formed for a type 1 gas hydrate. The authors also found a good fit to the data.

Based on the present study, we found that pectin reduces the rate of hydrate crystal growth and, as expected, the results also indicate that the pectin is a promissing inhibitor for methane hydrate formation. $\mathrm{Xu}$ et al. (2016a) also found that pectin could retard methane hydrate formation and suppress hydrate growth. According $\mathrm{Xu}$ et al. (2016a), the pectin has lots of oxygen or hydroxyl groups in its structure and, due that, it can form hydrogen bonds with water molecules, perturbing the water structure. They indicated that water molecules can break hydrogen bonds between hydroxyl and carbonyl groups of pectin through water and pectin molecules, forming $\mathrm{H}$ bonds. These effects result in a decrease in water activity and, after nucleation, the hydrophilic structure enables the pectin to retard hydrate crystal growth. Still, according to them, oxygen atoms of pectin bind to the surface of hydrate crystals through hydrogen bonds. As a consequence, the $\alpha$-D-galacturonosyl units of pectin can increase steric hindrance and, thus, suppress crystal growth.

The same behavior was observed by $\mathrm{Xu}$ et al. (2016b) for higher concentrations of pectin. Higher concentrations lead to better inhibition.

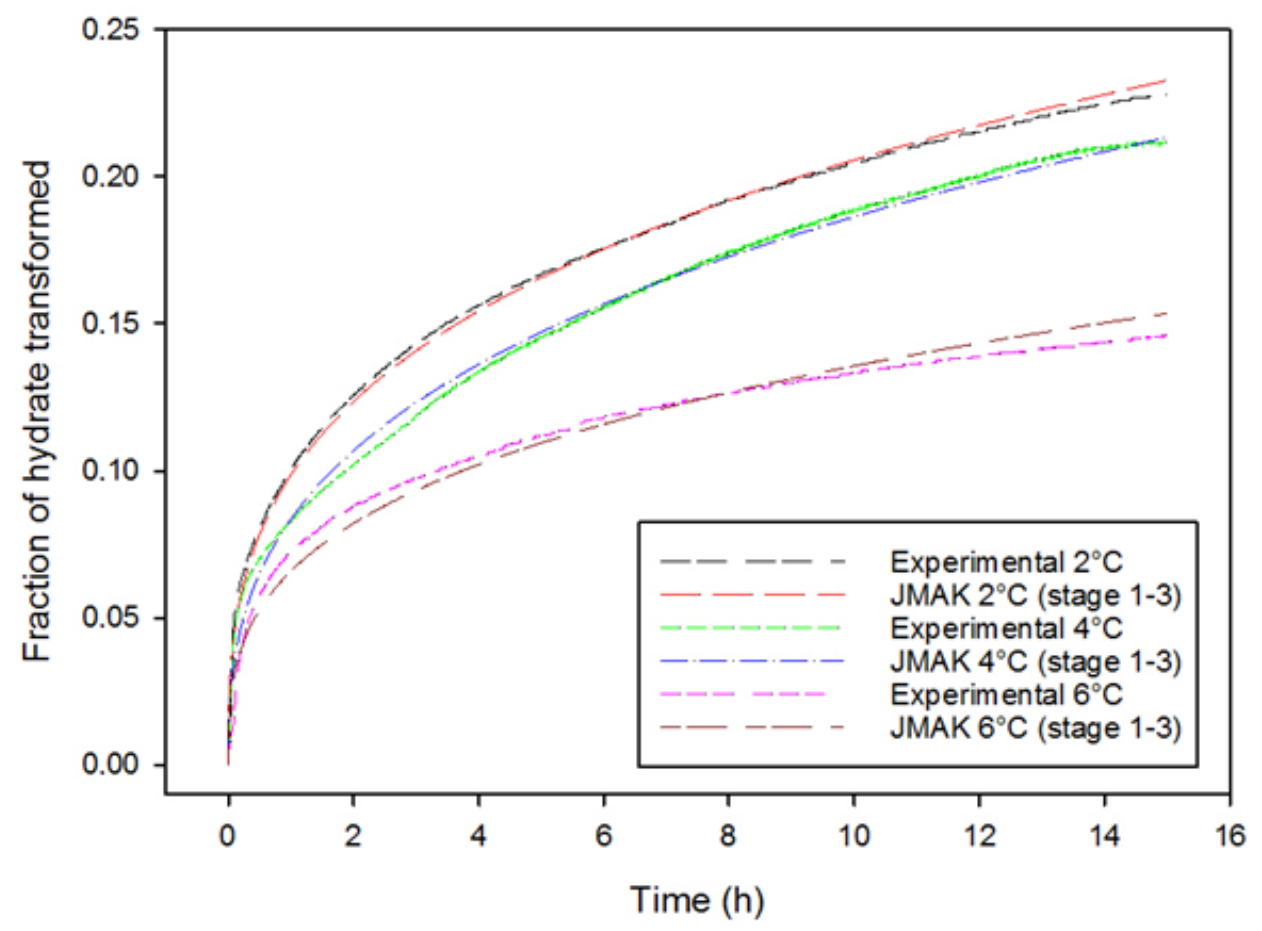

Figure 9. Fraction of hydrate formed for $1 \mathrm{wt} . \%$. 
Additionally, according to them, the doublebonded oxygen atoms of pectin combine with hydrogen atoms of water, and the hydrogen atoms of hydroxyl in pectin combine with oxygen atoms of water through hydrogen bonds, causing disturbance and affecting the growth of methane hydrate. They mentioned that the role of the active groups of pectin in hydrogen bonds with water, both as proton donor and as electron receptor, favors the pectin to have a better inhibitory effect on the growth of methane hydrate.

\section{CONCLUSIONS}

The results support that pectin has a kinetic inhibitory effect on hydrate formation. This proposition is demonstrated by the behavior of curves of pressure over time evolution. Experimental data indicates that presence of pectin reduces the rate of hydrate crystal growth. Gas consumption over time decreased on subcooling experiments. Increases in pectin concentration decreased the rate of gas hydrate formation.
Hydrate conversion rates were well correlated by the Avrami equation. The Avrami exponent " $n$ " was used to explain the hydrate nucleation and growth mechanisms. Thus, we reinforce that pectin is a promissing natural kinetic hydrate inhibitor with interesting applications in the oil and gas industry. We can also confirm that Avrami equation is a quite useful model for predicting the fraction of hydrate formed.

\section{ACKNOWLEDGMENTS}

The authors would like to thank CAPES and FAPERJ for the financial support and PETROBRAS/CENPES for the laboratory support.

\section{RESPONSIBILITY NOTICE}

The authors are the only responsible for the printed material included in this paper.

\section{APPENDIX A}

Figure A1: P-T equilibrium curve for mixture of methane and water.

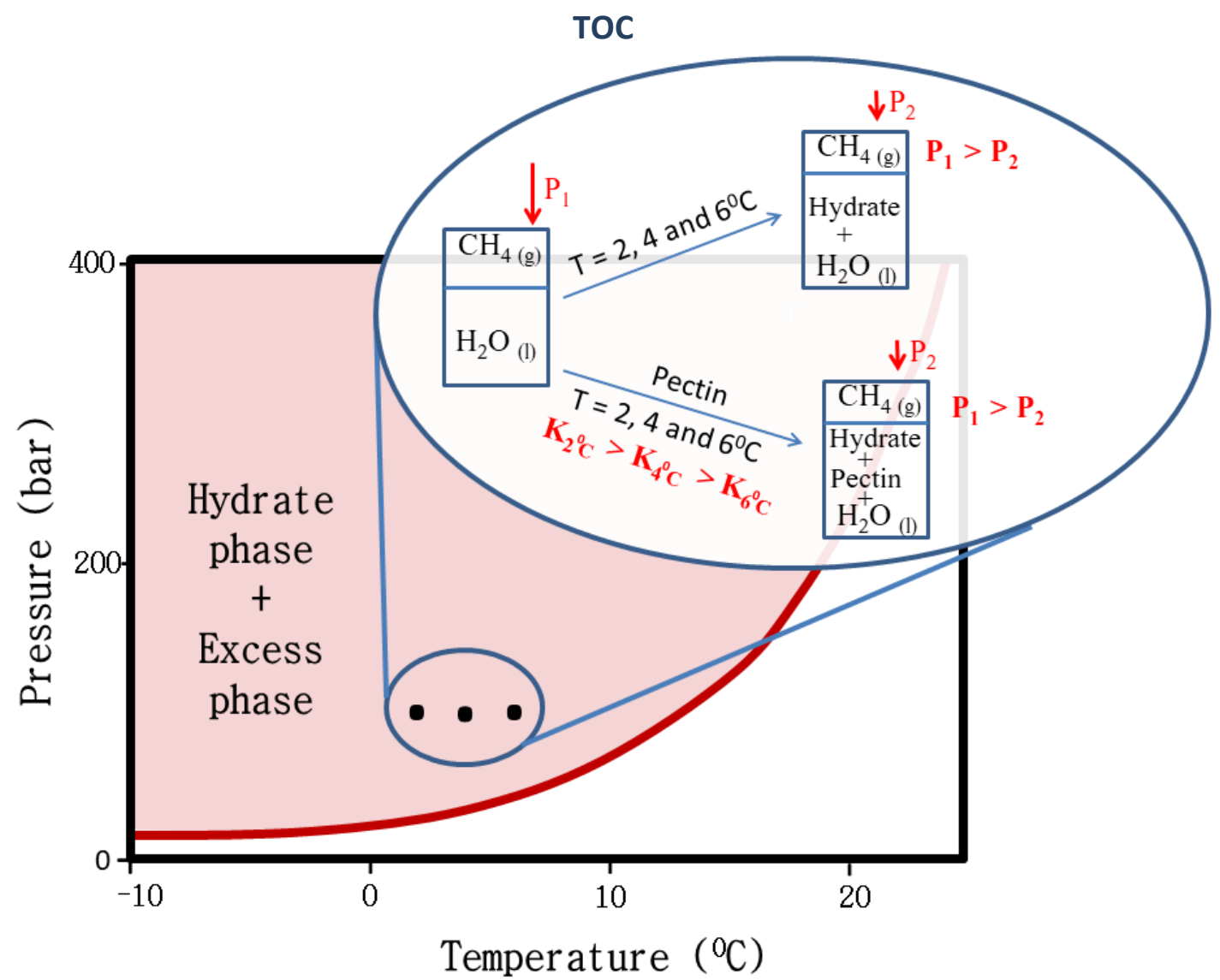

Figure A1. P-T equilibrium curve for mixture of methane and water. Decrease of pressure of $\mathrm{CH}_{4}(\mathrm{~g})$ of the system indicate the formation of gas hydrate where the presence of pectin acting as kinetic gas hydrate inhibitor gave a process with constant of hydrate formation that increase with temperature decrease from $\mathrm{T}=2^{\circ} \mathrm{C}$ to $\mathrm{T}=6^{\circ} \mathrm{C}$. 


\section{REFERENCES}

Amtawong, J.; Sengupta, S.; Nguyen, M. T.; Carrejo, N. C.; Guo, J.; Fleischer, E. B.; Martin, R.W.; Janda, K. C. Kinetics of trifluoromethane clathrate hydrate formation from CHF gas and ice particles. The Journal of Physical Chemistry A, v. 121, p. 7089-7098, 2017.

https://doi.org/10.1021/acs.jpca.7b08730

Bai, Y.; Bai, Q. Subsea Pipelines and Risers. Oxford: Elsevier, 2005.

Bai, Y.; Bai, Q. Subsea Engineering Handbook. Walthan: Gulf Professional Publishing, 2012. https://doi.org/10.1016/B978-0-12-397804-2.00012-6

Daraboina, N.; Linga, P.; Ripmeester, J.; Walker, V. K.; Englezos, P. Natural gas hydrate formation and decomposition in the presence of kinetic inhibitors. 2. Stirred reactor experiments. Energy \& Fuels, v. 25, p. 4384-4391, 2011. https://doi.org/10.1021/ef200813v

Daraboina, N.; Malmos, C.; Solms, N. V. Investigation of kinetic hydrate inhibition using a high pressure micro differential scanning calorimeter. Energy \& Fuels, v. 27, p. 5779-5786, 2013. https://doi.org/10.1021/ef401042h

Daraboina, N.; Linga, P.; Ripmeester, J.; Walker, V. K.; Englezos, P. The unusual growth behavior of methane/ethane/propane hydrate crystals in the presence of inhibitor at low pressure. In: Proceedings of the 8th International Conference on Gas Hydrates, Beijing, China, 2014.

Fanfoni, M.; Tomellini M. The Johnson-MehlAvrami-Kolmogorov model: A brief review. II Nuovo Cimento, v. 20, p. 1171-1182, 1998. https://doi.org/10.1007/BF03185527

Falenty, A.; Genov,G.; Hansen, T. C.; Kuhs, W. F.; Salamatin, A. N. Kinetics of $\mathrm{CO}_{2}$ hydrate formation from water frost at low temperatures: experimental results and theoretical model. Journal of Physical Chemistry C, v. 115 , p. 40224032, 2011. https://doi.org/10.1021/ip1084229

Gandara, R.; Liguori, F. A.; Casazza, F.; Rodeguer, M. G.; Maisonnave, P. P.; Bermann, C. Aproveitamento energético do hidrato de metano. In: 10 Congresso sobre Geração Distribuída e Energia no Meio Rural, São Paulo, Brasil, 2015.
Guo, X.; Zhao, W.; Pang, X.; Liao, X.; Hu, X.; Wu, J. Emulsion stabilizing properties of pectins extracted by high hydrostatic pressure, high-speed shearing homogenization and traditional thermal methods: A comparative study. Food Hydrocolloids, v. 35, p. 217-225, 2014.

https://doi.org/10.1016/i.foodhyd.2013.05.010

Kaschiev, D. Nucleation: Basic Theory and Applications. New York: Butterworth-Heinemann, 2000.

Khair, U.; Fahmi, H.; Hakim, S. A.; Rahim, R. Forecasting error calculation with mean absolute deviation and mean absolute percentage error. Journal of Physics, v. 930, p. 012002, 2017. https://doi.org/10.1088/1742-6596/930/1/012002

Kumar, A.; Khatri, D.; Lee, J. D.; Kumar, R. Crystallization kinetics for carbon dioxide gas hydrate in fixed bed and stirred tank reactor. Korean Journal of Chemical Engineering, v. 33, p. 1922-1930, 2016. https://doi.org/10.1007/s11814016-0040-7

Lee, J. D.; Wu, H.; Englezos, P. Cationic starches as gas hydrate kinetic inhibitors. Chemical Engineering Science, v. 62, p. 6548-6555, 2007. https://doi.org/10.1016/i.ces.2007.07.041

Nago, A.; Nieto, A. Natural gas production from methane hydrate deposits using clathrate sequestration: state-of-the-art review and new technical approaches. Journal of Geological Research, v. 2011, p. 239397, 2011. https://doi.org/10.1155/2011/239397

Oliveira, M. B.; Castro, J. A.; Silva, A. J. Formação de hidratos de gás em escoamento monofásico. In: Proceedings of the VI Congresso Nacional de Engenharia Mecânica, Campina Grande, Brazil, 2010.

Perfeldt, C. M.; Chua, P. C.; Daraboina, N.; Friis, D.; Kristiansen, E.; Ramlov, H.; Woodley, J. M.; Kelland, M. A.; Solms, N. V. Inhibition of gas hydrate nucleation and growth: efficacy of an antifreeze protein from the Longhorn Beetle Rhagium mordax. Energy \& Fuels, v. 28, p. 36663672, 2014. https://doi.org/10.1021/ef500349w

Ribeiro, C. P.; Lage, P. L. C. Modelling of hydrate formation kinetics: State-of-the-art and future directions. Chemical Engineering Science, v. 63(8), p. 2007-2034, 2008.

https://doi.org/10.1016/j.ces.2008.01.014 
Rios, P. R.; Padilha, A. F. Transformações de fase. São Paulo: Artliber, 2007. (in Portuguese)

Ripmeester, J. A.; Alavi, S. Some current challenges in clathrate hydrate science: Nucleation, decomposition and the memory effect. Current Opinion in Solid State and Materials Science, v. 20, p. 344-351, 2016.

https://doi.org/10.1016/i.cossms.2016.03.005

Sa, J. H.; Kwak, G. H.; Lee, B. R.; Park, D. H.; Han, K.; Lee, K. H. Hydrophobic amino acids as a new class of kinetic inhibitors for gas hydrate formation. Scientific Reports, v. 3, p. 2428, 2013.

https://doi.org/10.1038/srep02428

Sa, J. H.; Kwak, G. H.; Han, K.; Ahn, D.; Cho, S. J.; Lee, J. D.; Lee, K. H. Inhibition of methane and natural gas hydrate formation by altering the structure of water with amino acids. Scientific Reports, v.6, p. 31582, 2016.

https://doi.org/10.1038/srep31582

Siangsai, A.; Rangsunvigit, P.; Kitiyanan, B.; Kulprathipanja, S.; Linga, P. Investigation on the roles of activated carbonparticle sizes on methane hydrate formation and dissociation. Chemical Engineering Science, v. 126, p. 383-386, 2015. https://doi.org/10.1016/i.ces.2014.12.047

Silva, B. L. L. D.; Costa, B.S.; Garcia-Rojas, E.E. Binary and ternary mixtures of biopolymers and water: viscosity, refractive index, and density. International Journal of Thermophysics, v. 37, p. 79, 2016. https://doi.org/10.1007/s10765-016-2084-7

Tang, C.; Zhao, X.; Li, D.; He, Y.; Shen, X.; Liang, D. Investigation of the flow characteristics of methane hydrate slurries with low flow rates. Energy, v. 10, p.145, 2017. https://doi.org/10.3390/en10010145

Tian, Y.; Li, Y.; An, H.; Ren, J.; Su, J. Kinetics of methane hydrate formation in an aqueous solution with and without kinetic promoter (SDS) by spray reactor. Journal of Chemistry, v. 2017, p. 5208915, 2017. https://doi.org/10.1155/2017/5208915
Trueba, A. T.; Kroon M. C.; Peters, C. J.; Moudrakovski, I. L.; Ratcliffe, C. I.; Alavi, S.; Ripmeester, J. A. Inter-cage dynamics in structure I, $\mathrm{II}$, and $\mathrm{H}$ fluoromethane hydrates as studied by NMR and molecular dynamics simulations. The Journal of Chemical Physics, v. 140, 214703, 2014. https://doi.org/10.1063/1.4874636

Walker, V. K.; Zeng, H.; Ohno, H.; Daraboina, N.; Sharifi, H.; Bagherzadeh, S. A.; Alavi, S.; Englezos, P. Antifreeze proteins as gas hydrate inhibitors. Canadian Journal of Chemistry, v. 93, p. 839-849, 2015. https://doi.org/10.1139/cjc-2014-0538

White, G. W.; Katona, T.; Zodda, J. P. The use of high-performance size exclusion chromatography (HPSEC) as a molecular weight screening technique for polygalacturonic acid for use in pharmaceutical applications. Journal of pharmaceutical and biomedical analysis, v. 20, p. 905-912, 1999. https://doi.org/10.1016/S0731-7085(99)00083-7

Xu P.; Lang X.; Fan S.; Wang Y.; Chen J. Molecular dynamics simulation of methane hydrate growth in the presence of the natural product pectin. The Journal of Physical Chemistry C, v. 120, p. 5392-5397, 2016b.

https://doi.org/10.1021/acs.jpcc.5b10342

Xu, S.; Fan, S.; Fang, S.; Lang, X.; Wang, Y.; Chen, J. Pectin as an extraordinary natural kinetic hydrate inhibitor. Scientific Reports, v.6, p. 23220, 2016a. https://doi.org/10.1038/srep23220

Xu, Y. J.; Yang, M. L.; Yang, X. X. Chitosan as green kinetic inhibitors for gas hydrate formation. Journal of Natural Gas Chemistry, v. 19, p. 431-435, 2010. https://doi.org/10.1016/S10039953(09)60083-9 